\title{
TOWARDS MONOLITHICALLY PRINTED MFCS: DEVELOPMENT OF A 3D- PRINTABLE MEMBRANE ELECTRODE ASSEMBLY (MEA)
}

Pavlina Theodosiou ${ }^{a}$, John Greenman ${ }^{b}$ and Ioannis leropoulos ${ }^{a}{ }^{*}$

a Bristol BioEnergy Centre, Bristol Robotics Laboratory, University of the West of England, Bristol BS16 1QY, UK

${ }^{\mathrm{b}}$ Biological, Biomedical and Analytical Sciences, University of the West of England, BS16 1QY (UK)

*Corresponding Author: email: ioannis.ieropoulos@brl.ac.uk

\section{Abstract}

Additive manufacturing (3D-printing) and microbial fuel cells (MFCs) are two rapidly growing technologies which have been previously combined to advance the development of the latter. In the same line of work, this paper reports on the fabrication of novel membrane electrode assemblies (MEAs) using materials that can be 3D printed or extruded from the EvoBot platform. Materials such as air dry terracotta, air dry Fimo ${ }^{\mathrm{TM}}$ and standard terracotta were tested against conventional cation exchange membrane (CEM) material. The MEA was fabricated by painting the materials with custom made graphite coating. The results showed that the MFCs with the printable materials outperformed those using conventional CEM. Economic analysis showed that the utilization of ceramics-based separator can reduce significantly the overall costs. These findings suggest that monolithically printed MFCs may be feasible, as printable MEAs can improve MFCs performance, and help realise mass manufacturing at lower cost.

Keywords - MFC, EvoBot, Membrane electrode assembly, MEA, 3D-printing

\section{Introduction}

Renewable energy production from waste using microbial fuel cell (MFC) technology is attracting growing attention as the ever-increasing worldwide energy demand is projected to increase $28 \%$ by 2040 [1]. MFCs are bio-electrochemical devices that use microorganisms as biocatalysts to convert chemical energy stored in organic matter into electrical energy, and date back to 1911 [2,3]. MFCs consist of two electrodes, a positive cathode and a negative anode, which are separated by a semi-permeable membrane or salt bridge [4]. Microorganisms are inoculated in the anodic compartment and anaerobically are capable of oxidizing the substrate. Frequently in MFC studies, anaerobic sludge effluents are used to inoculate the cells due to their very diverse microbial community presence [5], however microorganisms that can transfer electrons via metabolism to an external electrode can be also found in pond water and soil samples [6]. The electrons are released, via a process called extracellular electron transfer (EET), to the anode electrode either directly or indirectly (using mediators). The two electrodes are connected by an external circuit, which allows the flow of electrons from the anode side to the cathode side where the reduction of oxygen occurs. However, MFCs are not only considered as infinite-life biological batteries [7] but also as promising wastewater (WW) treatment solutions [8] which can complement or substitute the existing WW treatment technologies. The latter is due to the bacterial decomposition of the 
organic matter or waste (eg. urine) in the MFC anodes which lowers the chemical oxygen demand (COD) in the effluent even by $95 \%$ in real life field applications [9].

Electricity production, COD removal, cost and durability of MFC systems is largely affected by and dependent on the materials used to build those units (or stacks) [10]. Anode materials have to satisfy different requisites in order to be suitable for MFCs applications. The material has to be electrically conductive, chemically and mechanically durable, low-cost and have high surface area to enhance the bacteria-electrode interface. Carbonaceous materials certainly are the suitable materials to fulfil these characteristics due to their cost efficiency and inertness towards bacteria [11-13]. Hence materials such as carbon fibre veil [11], carbon cloth [14,15], graphite felt [16,17] and carbon paper [18] have been extensively used in the MFC research. Similarly, the cathode materials must possess specific characteristics $[19,20]$ and ideally must have high redox potential and the ability to readily capture protons in order to facilitate the oxygen reduction reaction (ORR). Materials that fulfil those requirements are carbonaceous materials and non-corrosive metals, same as those mentioned above which are used as anode electrodes. Moreover, due to the sluggish ORR reaction occurring at the cathode, a catalyst needs to be integrated within the cathode structure [21]. Due to that, platinum group metals (PGM), platinum group metals-free (PGM-free) and metal-free high surface area carbonaceous materials have been investigated in the past as catalyst [22]. However, PGM are expensive and have limited lifetime, as they are prone to deactivation/poisoning reducing their activity and efficiency [23], therefore are not suitable for MFC applications. PGM-free catalysts based on transition metals instead, are more reliable and low cost compared to PGM. However, improvements are needed if they are to be employed for large scale applications [22]. Metal-free high surface area carbonaceous materials such as activated carbon have been recently heavily utilized with high durability, low cost and commercial availability at large scale [9,24]. Another similar material which has recently attracted an increasing interest due to its biocompatibility and economical nature, is the bamboo charcoal granules and tubes [25-27]. Lastly a material that plays a crucial role in high power performances is the current collector which is usually of the same nature as the electrode or can be a different material such as stainless steel mesh which provides mechanical strength and is corrosion proof [28].

In parallel, membrane materials are an important element within the microbial fuel cell system. Polymeric separator based on Nafion or Nafion-derived fluorinated polymers are considered the bottleneck of the MFC research and the main contributor to high cost and internal resistance [29]. Additionally, those types of membranes are prone to biofouling after long term operation (more than 60 days) $[30,31]$ which is a result of microorganisms, microbial extracellular polymers and salts depositing on the membrane. This, along with possibly contact resistance, impacts negatively the MFC power performance (up to $37 \%$ decrease) due to the deterioration of the cation transfer which limits the charge transfer and increases the systems' internal resistance (up to 20\%) [32]. Moreover, in the open-to-air configuration, the cathode is often not well integrated within the membrane, therefore the contact resistance is even higher, and output is limited. To overcome these issues, alternative MFC architectures and materials, such as ceramic based [33,34], need to be identified (or examined further) as well as ways to manufacture and integrate them. One possible design that can benefit the system is the integrated membrane electrode assembly (MEA) in which the cathode is built on the membrane itself. It was previously shown that the power output is improved by reducing the internal resistance [35]. 
MEA is the assembled system comprised of a membrane and an electrode/s attached together as one through pressing with or without heat treatment in order to minimise the distance between them. This arrangement has been inherited from traditional chemical abiotic fuel cell and showed higher power densities compared to the conventional separated membrane and electrode configurations [35]. However, only a few studies have focused on MEA influence on MFC systems and even fewer on 3D-fabrication techniques to manufacture these MEAs.

The present study looks at 3D printing MFCs using novel extrude-able materials that can be produced from the EvoBot platform; a Rep-Rap 3D printer turned to robot which can inoculate, maintain and print parts for MFCs [36]. The focus is on the development of cost-effective MEAs using extrude-able air-dry membranes coated with conductive paint. Different ceramic and polymeric based membranes were investigated and compared in terms of chemical composition and properties. The electrical conductivity, surface morphology and chemistry of the materials were also analysed. At last, the electrochemical performance in terms of power generation was measured and reported.

\section{Materials and Methods}

\subsection{Membrane Materials}

For the scope of this experiment, three types of potentially extrude-able membranes were tested and compared against a conventional cation exchange membrane (CEM) (Membranes International, USA). The materials tested were Fimo ${ }^{\mathrm{TM}}$ air-dry clay (Staedtler, German), terracotta air-dry clay (Hobbycraft, UK) and red terracotta modelling clay (Tiranti, UK). The latter was kilned at a temperature of $1070^{\circ} \mathrm{C}$ prior to use, to allow the structural bonding of the clay and ensure durability, whereas the other two were dried overnight at room temperature. All three membranes were prepared using the same process as previously described [37] and the thickness of the tested membranes was consistent for all the custom made membranes $(2.5 \mathrm{~mm})$. The total surface area of the membranes was $25 \mathrm{~cm}^{2}$. The control (CEM) membrane required activation in $5 \% \mathrm{NaCl}$ at $40^{\circ} \mathrm{C}$ for 12 hours prior to use. The images of the different membranes utilised in this study are shown in Figure 1.

\subsection{Membrane electrode assembly}

A conductive graphite coating was applied to each membrane and formed the cathode electrode. The coating was fabricated using polyurethane rubber coating (PlastiDip), white spirit and graphite powder as previously described [38]. The membranes were coated uniformly with the conductive cathode mixture using a brush followed by the Dr. Blade technique using a spatula. The surface resistance was measured during each coating (Section 2.3.4). After the membrane electrode assembly had dried, a cable was attached to the cathode using conductive wire glue, to form the cathodic current collector.

\subsection{Characterization of membrane and electrode}

\subsubsection{Chemical composition of the membranes}


A qualitative chemical analysis of the membranes was determined using the Oxford Instruments Aztec energy dispersive X-ray (EDX) system and the main elemental content of each membrane sample was identified.

\subsubsection{Morphology of the electrode}

Surface morphology of the electrode side of the MEA was acquired through images using FEI Quanta 650 field emission scanning electron microscopy (SEM) at difference magnifications.

\subsubsection{Hardness test}

The hardness of the membranes materials was tested using the Vickers Hardness Testing equipment [39] (Buehler, UK). Particularly; the entire $25 \mathrm{~cm}^{2}$ of the membrane was used for the hardness testing. Average values were obtained from five readings taken from five different locations on the membrane and located $5 \mathrm{~cm}$ apart.

\subsubsection{Electrical conductivity of the cathode multiple layers}

The in-plane conductivity of the cathode was measured through a handheld digital multimeter (TENMA, 72-7750). Particularly, crocodile clips were attached on the opposite sides of the membrane electrode assembly and the resistance was measured. This operation was repeated for each layer of graphite applied on the membrane. This method was only used to give an early indication of the in-plane resistance of each conductive coating addition.

\subsection{MFC architecture}

Four triplicates of analytical size MFCs were assembled for this experiment. Each MFC The MFCs were constructed using one side of a covered $15 \mathrm{~mm}$ thick Polymethyl methacrylate (Perspex) sheet. The anode electrode was a folded carbon veil fibre $\left(20 \mathrm{gm}^{-2}\right.$ carbon loading) with a projected area of $8.45 \mathrm{~cm}^{2}$ and total surface area of $270 \mathrm{~cm}^{2}$ (PMF Composites, Dorset, U.K.). The cathode was integrated with the four different membranes and directly glued to the anode chamber with an inert aquatic sealant (Aquabits, UK). In order to maintain the moisture of the membrane electrode assemblies and maintain a liquid 'bridge' for proton transport, the MFCs were wrapped with Parafilm ${ }^{\circledR}$ which is a highly waterproof material but at the same time is permeable to oxygen (Figure 1.A).

\subsection{Inoculation and feedstock}

The twelve MFCs were inoculated with a mixture of $50 \%$ fresh human urine collected anonymously from healthy individuals and $50 \%$ anolyte derived from already established experiment operating on activated sludge (Wessex Water, UK) and urine. The mixture was enriched with a background solution of TYE which was comprised of tryptone (1\%) and yeast extract $(0.5 \%)$ as nutrient and amino acid supplier. The solution was left in a shaking incubator (Orbital Incubator S150) for 24 hours at a shaking speed of $130 \mathrm{rpm}$ and at a temperature of $36.6^{\circ} \mathrm{C}$. The solution was transferred to $15 \mathrm{~mL}$ centrifuge tubes (Corning, UK) and placed into the centrifuge (VWR Compact Star CS4) for 10 minutes at 5000rpm. Subsequently, the supernatant was removed and the pellet re-suspended into $5 \mathrm{~mL}$ of neat urine. The resuspended medium was collected and formed the inoculum for the experiment. After inoculation period when the biofilm formed, the MFCs were fed manually in batch mode with 
urine. The experiment was performed at room temperature $\left(22 \pm 2{ }^{\circ} \mathrm{C}\right)$ within a temperaturecontrolled environment.

\subsection{External resistance and polarization experiment}

The MFCs operated in a fixed load of $2.7 \mathrm{k} \Omega$ prior to polarization experiment, which was conducted on the MFCs by connecting them to 8-channel automated Resistorstat equipment, developed as described in Degrenne et.al. [40]. The external resistance ( $\left.R_{\text {ext. }}\right)$ was ranging decreasingly from $30 \mathrm{k} \Omega$ to $3.74 \Omega$ with each resistance value held for 3 minutes. During polarization, voltage output was recorded every $30 \mathrm{~s}$ ( 6 samples per resistance value) to make it possible to monitor and capture the dynamic response of MFC to changes in $R_{\text {ext. }}$. The MFCs were kept in open-circuit voltage for 2 hours prior to polarization testing. Following the first polarization experiment the $R_{\text {ext }}$ was changed to $1 \mathrm{k} \Omega$, a value at which maximum power was generated. This load was kept constant until the end of the experiment.

\subsection{Data recording and calculations}

The MFCs were individually connected to an Agilent Keysight 34970A Data Acquisition / Data Logger Switch Unit (Keysight Technologies, UK) for data recording of voltage $(\mathrm{mV})$ against time with readings taken every 3 minutes. The data were processed and analysed using MS Office Excel where current $(I)$ in amperes (A) was calculated in accordance with the Ohm's Law; I = V/R, where $V$ is the measured voltage and $R$ is the known value of the external resistive load in ohms $(\Omega)$. Power $(P)$ values in watts $(W)$ were calculated by multiplying voltage with current: $P=I \times \vee[41]$.

\subsection{COD measurements}

Chemical oxygen demand (COD) removal analysis was carried out on the forty-second day of the experiment by analysing the influent sample and comparing it with the effluent sample after 24 hour retention time in the MFC. The analysis were conducted using the potassium dichromate oxidation method (CamLab, UK) with high range (HR) COD vials in which $0.2 \mathrm{~mL}$ of sample to be analysed (inlet and outlet) was taken from the MFC and filtered before being added into the vial. The sample was then heated up at $150^{\circ} \mathrm{C}$ for 2 hours and cooled down for another 2 hours. At last, the concentration was measured through a spectrophotometer (Lovibond Water testing).

\subsection{Breakdown of the experimental procedure}

The experimental plan that was followed in this study has been summarised and presented at Table 1. The table notes in detail the feeding regime followed, the operational conditions, urine replacements, timings and quantities of feedstock as well. 
Breakdown of the experimental scheme

\begin{tabular}{r|lll} 
Day 0 & Inoculation & $\begin{array}{l}100 \% \text { inoculum } \\
50 \% \text { inoculum }-\end{array}$ & Full exchange $(25 \mathrm{~mL})$ \\
Day $1-2$ & Inoculation & $\begin{array}{l}50 \% \text { urine } \\
\text { No feeding }\end{array}$ & - \\
Day $3-4$ & - & $100 \%$ urine & Full exchange $(25 \mathrm{~mL})$ \\
Day $5-9$ & Daily Feeding & $100 \%$ urine & $5 \mathrm{~mL}$ top-up
\end{tabular}

Day 15 onwards feeding regime: a complete exchange of anolyte early each week, followed by a daily top-up of $5 \mathrm{~mL}$ until the end of the week.

\begin{tabular}{r|lll} 
Day 15-25 & Daily feeding & Water diluted urine & Feeding regime described above \\
Day 26-30 & Daily feeding & $100 \%$ urine & Feeding regime described above \\
Day 30 & Polarization & Change of Rext. from $2.7 \mathrm{k} \Omega$ to $1 \mathrm{k} \Omega$ \\
Day 31-58 & Daily feeding & $100 \%$ urine & Feeding regime described above \\
Day 59-62 & Starvation period & No feeding & - \\
Day 63-73 & Daily feeding & $100 \%$ urine & Feeding regime described above
\end{tabular}

Table 1. Breakdown of the experimental scheme followed through the entire duration of the experiment.

3. Results and Discussion

202

\subsection{Material selection}
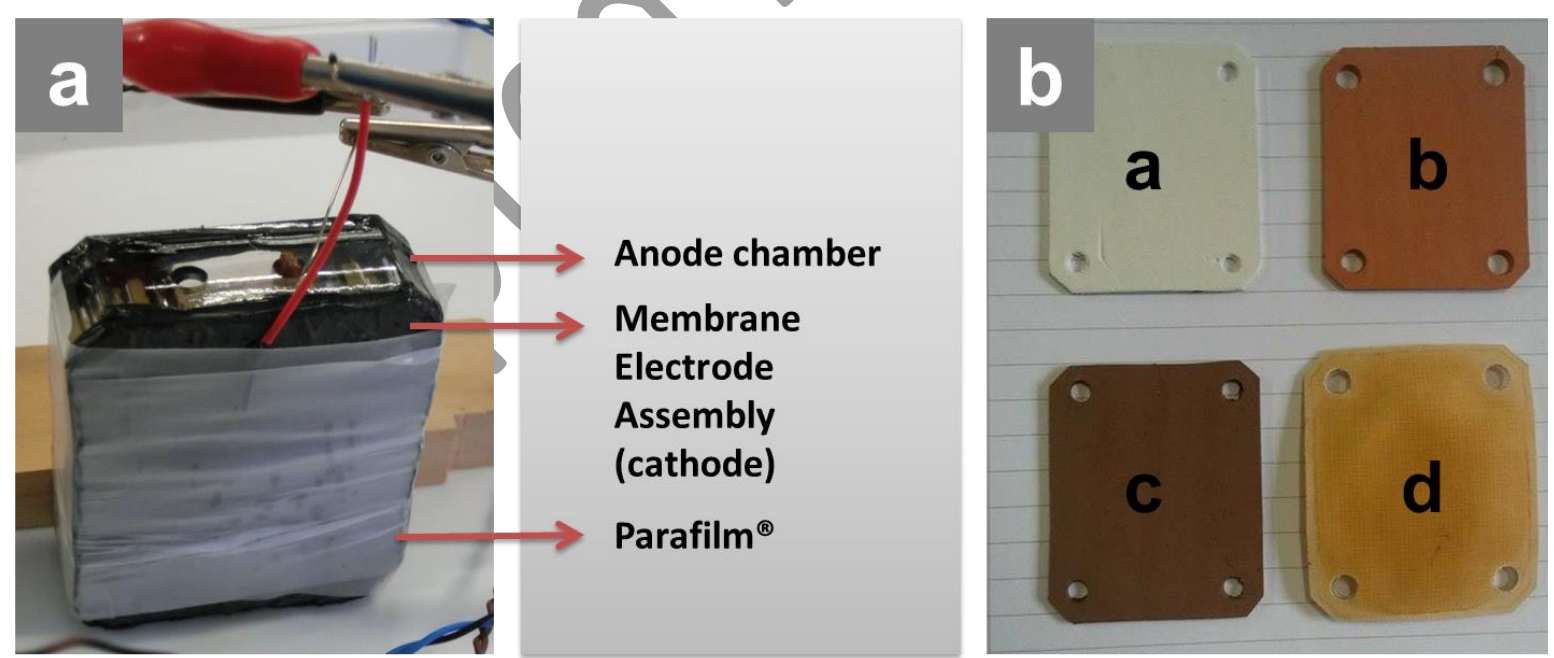

Figure 1. Photographs of a) the MFC set-up and b) the four cut-to-shape membrane materials Air-dry Fimo ${ }^{\mathrm{TM}}$ (a), Air-dry Clay (b), Terracotta (c) and Cation exchange membrane (d).

Four different membranes (Figure 1.B) were selected and investigated as separators in MFCs fed with urine. Two of the membranes were based on air-dry techniques and were Fimo ${ }^{\mathrm{TM}}$ airdry clay and terracotta air-dry clay. These two materials were selected due to the advantage of being extrude-able from an adapted 3D-printer nozzle, which can be incorporated in the EvoBot platform. Furthermore, the air-drying technique allows fabricating ceramics just 
through normal atmospheric conditions without the utilization of heat treatment. Red terracotta modelling clay was another membrane used for this experiment and acted as a control to the investigation. However terracotta was subject to high temperature treatment in controlled atmospheric conditions which allowed the internal binding of the clay within the structure as needed [37]. The last membrane utilized was a commercial polymeric-based cation exchange membrane.

\subsection{Material analysis}

\subsubsection{Chemical composition of the membranes}

Energy dispersive X-ray (EDX) system was used for the qualitative chemical analysis of the elements composing each membrane tested during this investigation. $\mathrm{C}, \mathrm{O}, \mathrm{Al}$, Si and $\mathrm{F}$ were the elements identified with percentages above 10\% (Figure 2.A). Carbon and oxygen were detected in all four samples, however it is notable that aluminium and silicon were detected only for the ceramic-based membranes. These elements are well known to be generally integrated within ceramic materials especially in their oxide form [42]. As expected fluoride was only detected in the polymeric membranes. Generally, polymeric membranes are composed by a backbone of fluorinated polymer that gives mechanical strength and resistance to harsh and corrosive environments. Unfortunately, $\mathrm{F}$ is not environmentally friendly and therefore the utilization of fluorinated materials in microbial fuel cells might negatively impact the environment after long terms operations. In fact, if those MFCs are to be used on-board low-power robots that are programmed to perform a particular task and then degrade naturally in the environment [43] then the use of fluorinated membranes needs to be avoided.

Additionally, elements with percentage lower than $5 \%$ were also reported (Figure 2.B). Traces of $\mathrm{Na}, \mathrm{Mg}, \mathrm{K}, \mathrm{Ca}, \mathrm{Ti}$ and $\mathrm{Fe}$ were detected within the ceramic-based samples. Only $\mathrm{Na}$ and $\mathrm{N}$ were detected on the polymeric membrane. Interestingly, a percentage of $\sim 3.5 \%$ of Ca was measured in the air-dry clay and higher content (roughly $4 \%$ ) of iron was detected in the terracotta sample.

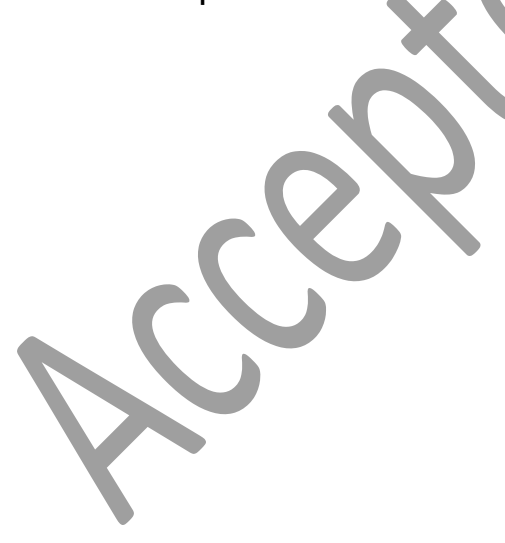




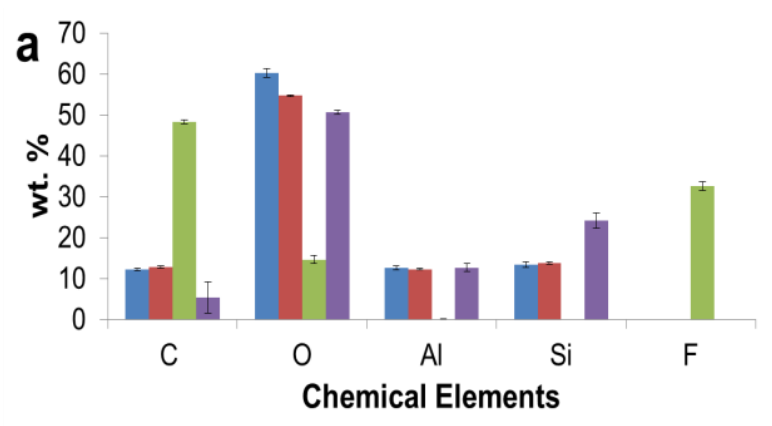

$\|$ Air-dry Fimo $=$ Air-dry Clay $\approx$ Cation Exchange Membrane $=$ Terracotta

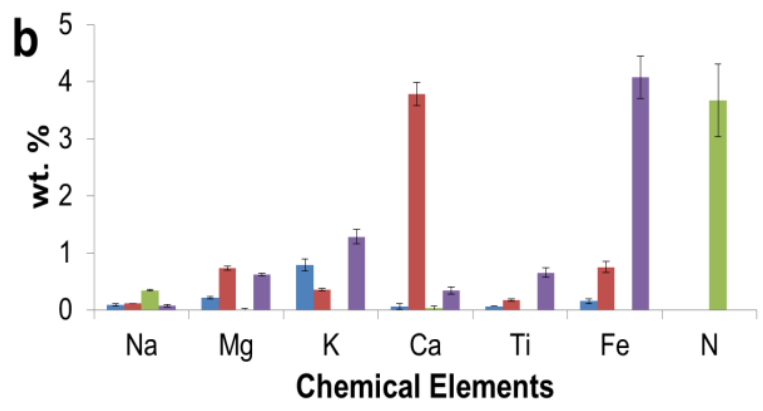

$\|$ Air-dry Fimo $=$ Air-dry Clay $\approx$ Cation Exchange Membrane $=$ Terracotta

Figure 2. ED-X analysis results data of the chemical elements between the four tested types of membranes. a) Major and minor components b) trace elements.

\subsubsection{Morphology of the electrode}

238 The morphology of the graphite-based coating was observed using SEM images at different

239 magnifications (Figure 3). Increasing magnifications allowed visualising the surface of the 240 electrode in more detail. The surface of the electrode in fact seems to be fully covered by a 241 quasi-uniform coating. At higher magnification, the graphite particles could be clearly detected with non-uniform shape and length within the micrometric shape in agreement with the manufacturer's specifications [44]. 


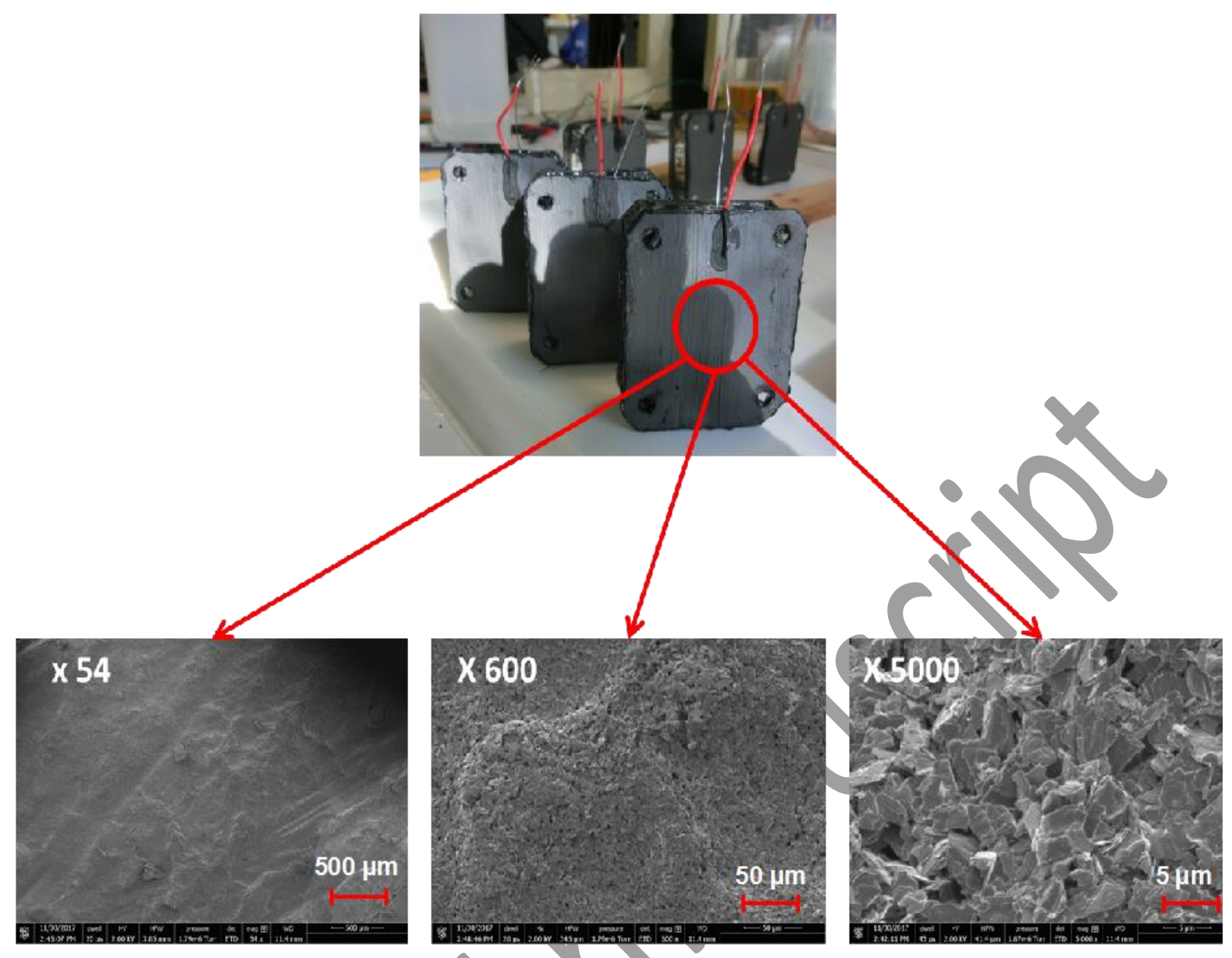

Figure 3. SEM images at three different magnification of the MEA side surface coated with the graphite ink (cathode side).

\subsubsection{Electrical conductivity of the cathode multiple layers}

The MEAs were prepared by applying the conductive ink directly on to the already set membranes using a layer-by-layer technique akin to a 3D-printer approach. Each layer was left to air-dry before each in-plane measurement of resistance was taken. Figure 4.A. shows the in-plane resistance of the air-dry clay and terracotta clay based MEAs after applying the first, second and third layer of conductive ink on their surfaces. Those two sets of data were chosen to be discussed as they illustrate nicely the initial difference in resistance between the two differently made clays (air dry and kilned). Initially the terracotta MEA had almost $2.5 \mathrm{x}$ higher resistance compared to air-dry clay. The difference in resistance became larger after applying the second layer of coating with terracotta being $5.0 \times$ higher that air-dry clay even though the overall resistance decreased for both by nearly $2.0 \times$ and $4.0 x$ respectively. Despite the differences and high resistance values initially, by the time the third layer of conductive coating was applied and cured, both MEAs showed similar in-plane resistance $(170 \pm 5 \Omega)$. This suggested that by that time the conductive ink coating covered completely the surface of the membrane and bonded with the underlined layers of coating in a quasi-uniform manner, in agreement with the SEM micrographs. It is noteworthy that in an attempt to decrease the in-plane resistance even more, a fourth layer of coating was applied on the membranes however this had an adverse effect on the continuity of the electrode as it caused cracking of the upper layer of coating (data not shown). Thus for the scope of this experiment only three layers of coating were applied on each membrane and form the MEA, which was in 
accordance to what has been reported in the literature for similar conductive inks applied on paper-based MFCs [45]. Following the application of three consecutive layers of conductive ink on the MEAs the in-plane resistance values were measured and plotted on Figure 4.B showing that all MEAs had an overall resistance of $150 \pm 15 \Omega$. More specifically, Fimo ${ }^{\mathrm{TM}}$ had an in-plane resistance of $135 \Omega$ followed by CEM with a resistance of $143 \Omega$, air-dry clay and terracotta as mentioned above had a similar resistance of 158 and 168 ohms, respectively. These results have given an initial indication of the in-plane resistance after each layer of graphite coating, which can provide information on the current connecting losses of the MEA. In further investigation of MEA materials, through-plane resistance it is recommended to be measured in order to provide more comprehensive results on the whole MEA resistance. 

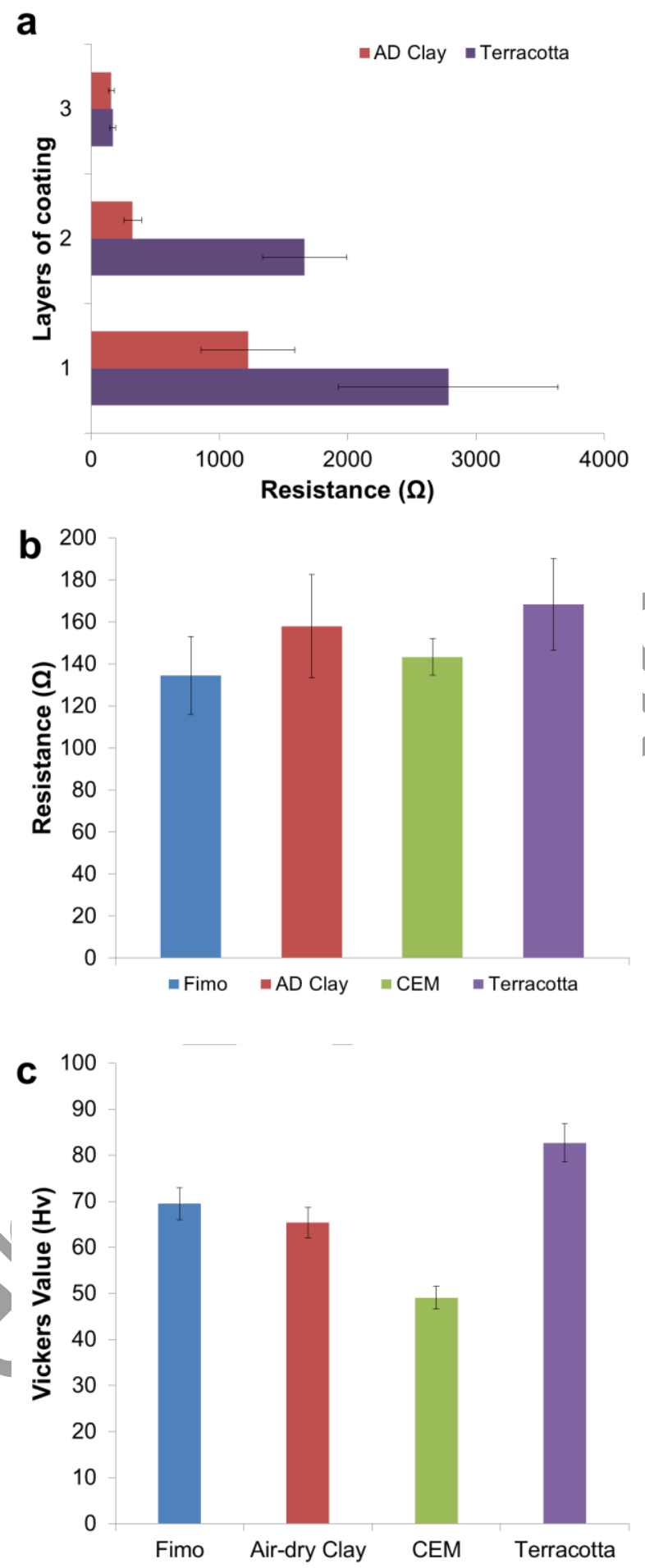

Figure 4. Resistivity of the MEA and hardness of the membrane. a) average resistance values after each coating on the membrane b) average surface resistance of the MEA electrode c) hardness test based on Vickers value (Hv).

275 It is well known from the literature that ceramics possess many unique characteristics that 276 make them suitable for use within MFC systems; one of these advantageous characteristics 277 is their structural durability [33]. In order to test the durability of the materials under 278 investigation against terracotta, a Vickers hardness test was performed. Even though this 279 technique is well used for testing metal materials, it has been reported in the past that it can 280 be used for ceramic materials [39] to give an indication of durability between different samples. 
The unit of hardness given by this test is the Vickers Pyramid Number (HV), the five values obtained from each ceramic testing were averaged and presented in Figure 4.C. The results confirmed that terracotta was indeed the most durable/hardest $(82.7 \mathrm{HV})$; however air-dry Fimo $^{\mathrm{TM}}$ and air-dry clay were only 13 and $17 \mathrm{HV}$ units more fragile, respectively. To put the results into perspective a diamond has a hardness value of $10000 \mathrm{HV}$. Those data are an early indication that even though air-dry clays are not as structurally robust as kilned terracotta, they can still be proven to be durable. The hardness of the materials was tested in order to observe the properties of the material in question, in terms of deformation from a standard source (the metal indenter), which would in turn provide an indication of the material's ability to resist wear, pressure, or damage, which is particularly relevant for shipping systems like these to other areas.

\subsection{Power Output}

\subsubsection{Initial power output profile of the first fifteen days}

For this experiment, MFCs using different membrane materials were tested with the ultimate aim to observe the feasibility of using air-dry clays that can be 3D-printed, as separators for MFCs. As previously mentioned (Section 2.5), the MFCs were all inoculated with a mixture of activated sludge, tryptone yeast extract and effluent from established urine fed MFC experiments. After inoculation, the MFCs were left in open circuit for three hours until the voltage plateaued. The observed potential difference between the anode and cathode from all the MFCs was roughly $600 \pm 50 \mathrm{mV}$ (data not shown). An external load of $2.7 \mathrm{k} \Omega$ was connected on all MFCs, closing the circuit and initiating the power generation process by encouraging the formation of an electroactive biofilm on the anode electrode. The MFCs were maintained in a batch fed mode. Each feeding can be simply identified on the graph as every time a feeding occurred, an instant increase -followed by gradual decrease- in power output can be observed. This is reflected by the fact that the energy source availability within the anode chamber increased, meaning that bacteria have fresh and available organic matter to metabolise. The first two exchanges in anolyte consisted of replenishing fully the chamber with the aforementioned inoculum and urine in a 50\%:50\% ratio, which was sufficient to supply the bacteria with the much needed carbon energy sources to continue their metabolic activities during "periods of no feeding", which were beyond the normal feeding cycle (Figure 5). During this period, the MFCs with air-dry clay membrane decreased in performance by $13.2 \%$, which was similar with the air-dry Fimo ${ }^{\mathrm{TM}}(13.8 \%$ decrease). The MFCs with terracotta and CEM were the most affected showing a decrease of $18.6 \%$ and $40.0 \%$ respectively.

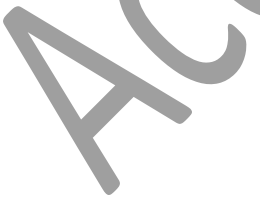




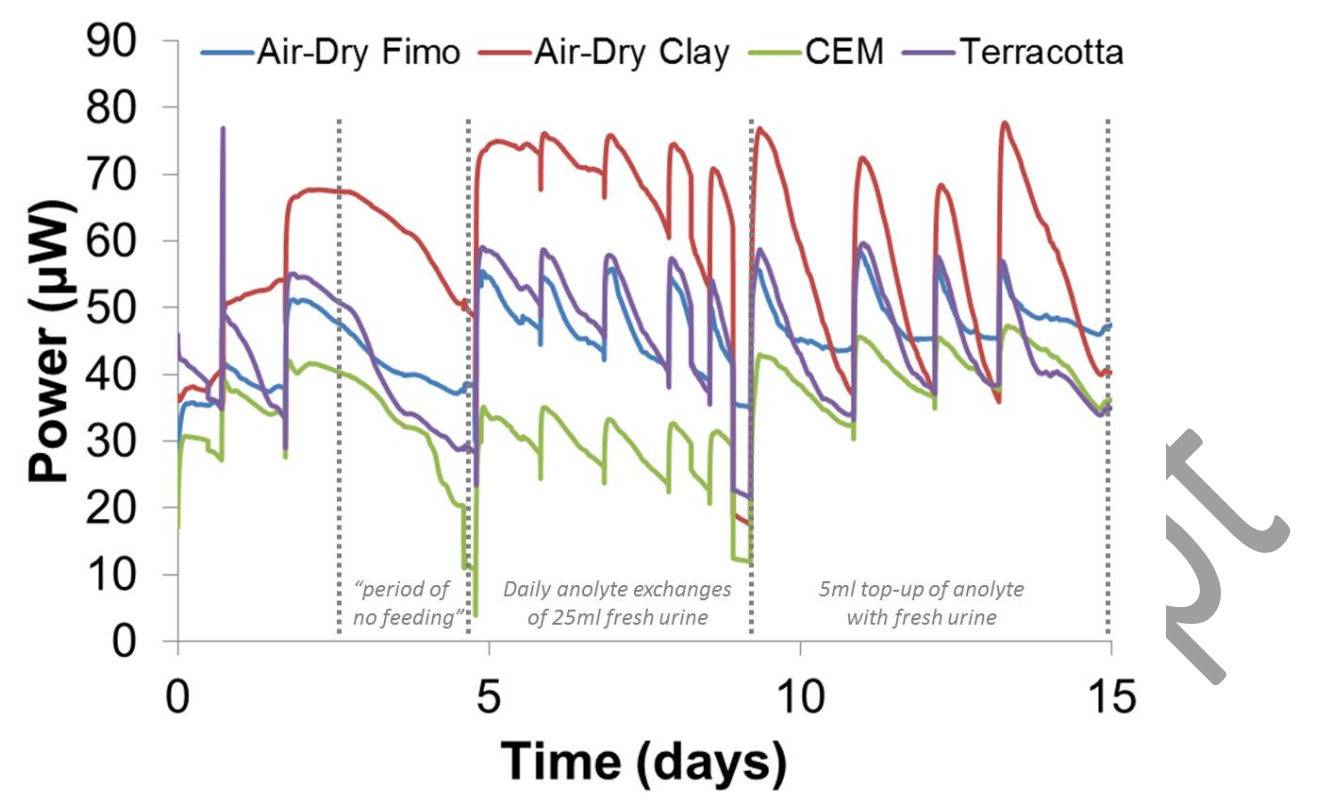

Figure 5 Power generation recorded in the first 15 days of operations.

On the fifth day, the anode chamber of each MFC was replenished completely $(25 \mathrm{~mL})$ with fresh urine that resulted in increasing the power output by $14.4 \%$ and $14.8 \%$ on the air-dry clay based MFCs, $29.7 \%$ for the CEM based MFCs and nearly $50 \%$ in the terracotta based MFCs (Figure 5). It is assumed that the terracotta based MEA had the greatest improvement in power following carbon-energy depletion, because of the higher porosity compared to the other materials, which has a direct impact on the cation rate of exchange. Higher porosity, and non-selective materials will naturally allow a higher rate of cations to diffuse through - a process which is driven by electron-neutrality. This means that for selective or lower porosity materials even if the rate of electrons generated by the biofilm communities is at similar levels for all tested conditions, the power output will be lower, as a result of the lower number of cations, diffusing through the membrane and reacting with the incoming electrons. This is also reflected by the fact that the terracotta based MEAs reached maximum power output just after 5 days of operation[42] whereas the other materials needed more time to reach that. The next five days continued with daily anolyte exchanges of $25 \mathrm{~mL}$ fresh urine as indicated by the spikes on the graph. During this period, the MFCs showed consistent increase in power output with a peak at $75 \mu \mathrm{W}$ for air-dry clay followed by terracotta and air-dry Fimo ${ }^{\mathrm{TM}}$, which were almost on a par at $58 \mu \mathrm{W}$ and $54 \mu \mathrm{W}$, respectively; the CEM was the least performing with 37 $\mu \mathrm{W}$. Nine days after the start of the experiment and the daily complete emptying and refilling of the anode chambers with fresh organic matter, the mode of feeding was switched to $5 \mathrm{~mL}$ top-ups, after manually removing the same liquid volume from each anode. This had as an impact the overall increase in power output of the MFCs by $11 \%-15 \%$, however performance would decrease much faster due to the lower amount of fresh carbon-energy available. Bacteria were presumably still consuming other by-products available in the suspension within the 24 hour window between each feeding- however the power output at the end of each feeding cycle was consistently at the same level of $40 \mu \mathrm{W}$ each time. In order to compensate for the impact of each feeding approach on the power performance, it was 
decided to have a complete exchange of anolyte early each week, followed by a daily top-up of $5 \mathrm{~mL}$ until the end of the week. This strategy was followed until the end of the experiment.

\subsubsection{Long term power output profile of the entire experiment duration}

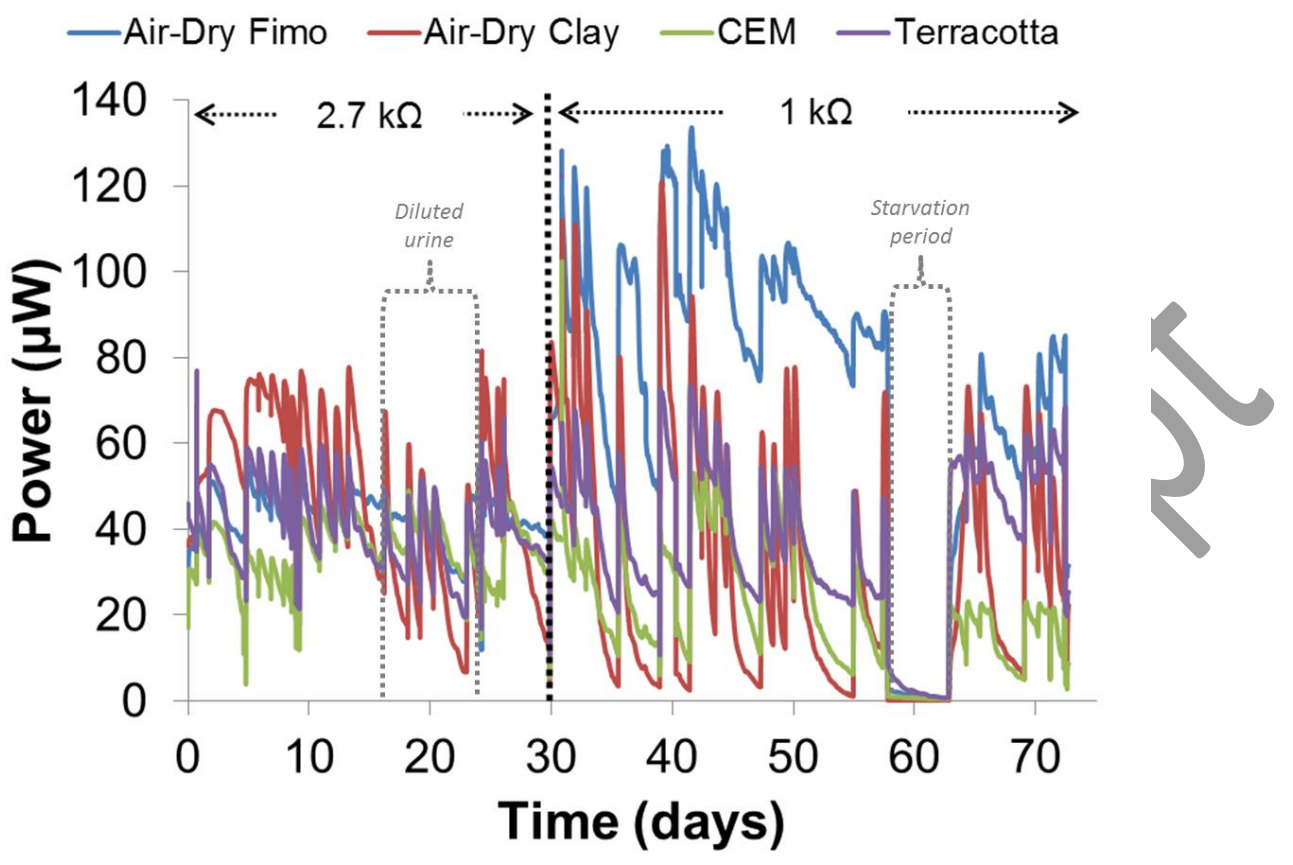

Figure 6. Power generation over 70 days operations

As explained earlier, the experiment was maintained at a constant external load of $2.7 \mathrm{k} \Omega$ for the initial 30 days of operation, during which it was clearly observed that the air-dry clay was the best performing, while the air-dry Fimo ${ }^{\mathrm{TM}}$ and terracotta were on a par; in most cases CEM was the least performing. Although a steady-state was achieved within the first fifteen days of operation for all the MFCs, this was lost due to urine shortage and having to use diluted urine (50:50) between the fifteenth and twenty-fourth day of the experiment (Figure 6). It is envisaged that the steady state was going to be continued at the same levels if neat urine had been supplied to the bacteria. This hypothesis is confirmed by the data of the twenty-fifth day where the output of the MFCs recovered to the previous levels once un-diluted neat urine was supplied. Following a month of operation at a constant load, the MFCs were subjected to polarization using an automated Resistorstat as explained previously (Section 2.6) in order to identify the optimum resistance value based on each system that can give the maximum power output. Although the polarization results are discussed in detail below (Section 3.2), the impact of identifying and applying the optimum external load on the MFCs will be discussed here. The results of the polarization experiment showed that those particular MFC systems can operate at their best when they are subjected to an external loading of $1 \mathrm{k} \Omega$ resistance. Once the external resistance switched to $1 \mathrm{k} \Omega$, Fimo ${ }^{\mathrm{TM}}$ outperformed the rest and the overall power output of all others also increased by $25 \%-50 \%$. The performance of the MFCs was maintained at the same levels for the following month until a complete starvation of four consecutive days brought all the systems to nearly zero (from day 58 to day 62). During this period, all the anode MFC chambers completely dried out from evaporation (Figure 6). However, once the MFCs were fed again, the bacterial communities of the already established anode biofilm switched from inactive mode (carbon limited) to active mode. Therefore, the power performance recovered immediately back to similar levels as those from the last 
feeding. More specifically, Fimo ${ }^{\mathrm{TM}}$ separated MFCs reached $91.25 \%$ recovery, air-dry clay and CEM reached full recovery $(100 \%)$, while interestingly terracotta separated MFCs had an increase of $13.4 \%$. However compared to the highest levels of performance recorded during days $30-45$, the percentage of recovery was $63.5 \%, 64 \%, 40.5 \%$ and $91 \%$ for Fimo ${ }^{\mathrm{TM}}$, air-dry clay, CEM and terracotta respectively. The recovery profile of the previously dried and inactive MFCs adds an extra value to the feasibility of those systems. MFCs are biological entities that not only have long-term power production capabilities -for as long as organic matter is supplied- but more importantly, can survive elongated periods of starvation with demonstrable fast response/recovery. In addition, inexpensive materials such as air-dry clays and terracotta can be used to make these MFCs, which is an economic advantage over traditional commercially available ion exchange membranes.

\subsubsection{Polarization results}
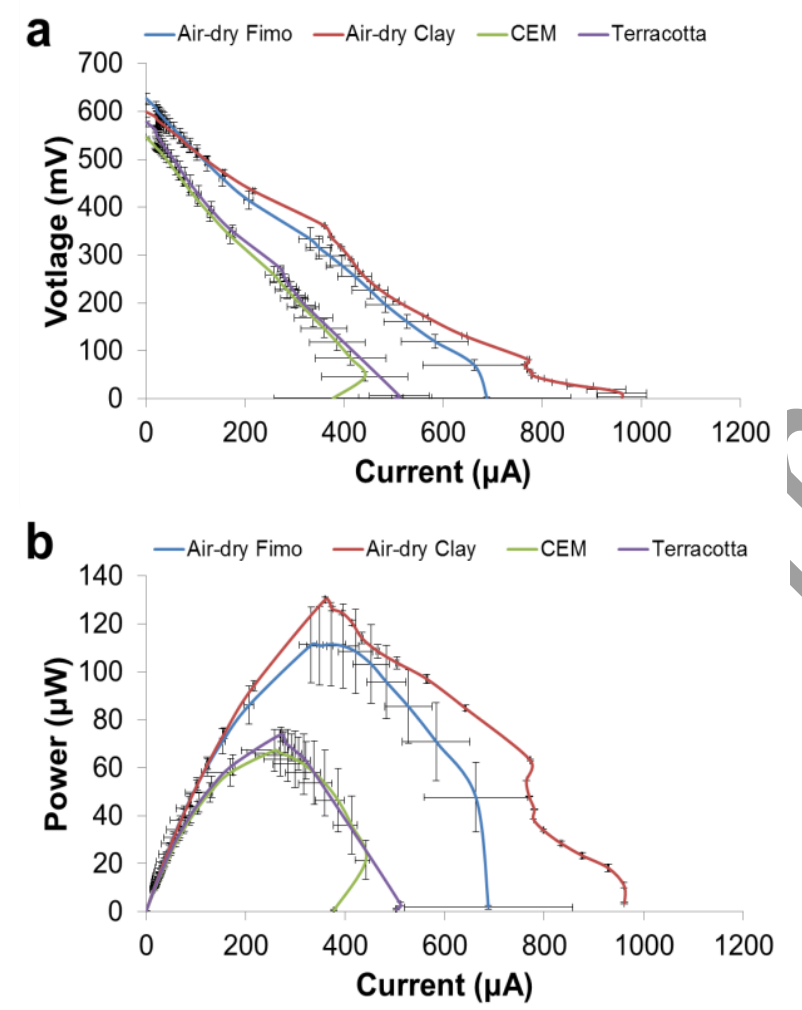

Figure 7. Polarization results a) voltage vs current curve and b) power curve. Error bars are shown for all conditions

After a whole month of operation under a constant load $(2.7 \mathrm{k} \Omega)$, all the MFCs were subjected to polarization analysis by sweeping the external resistance value in a gradual manner starting from infinite resistance (open circuit) and finishing at a very low resistance value (heavy load). Throughout the polarization experiment, the voltage output of the cells was recorded as a function of resistance, which made it possible for the automated system to calculate the current and subsequently the power output. Using the aforementioned data a polarization curve (Figure 7.A) was generated by plotting the voltage versus current. The recordings from each triplicate of MFCs were averaged and plotted including the standard deviations. The initial values at $1 \mathrm{M} \Omega$ resistance (no current) show the open circuit voltage (OCV) of all the 
theoretical OCV value $(1.1 \mathrm{~V})$ for open-to-air cathode MFCs primarily due to activation overpotentials, which is a characteristic of MFCs with air-breathing cathodes, which operate on the oxygen reduction reaction (ORR); this is limiting when occurring in neutral media [22]. These OCV values are in agreement with other open-to-air MFC devices under similar operating conditions $[13,46]$. Although in the literature there are also higher OCV values reported (0.7-1.0 V), the cathode electrodes of those MFCs were either supplemented with ferricyanide, during the polarization experiment, or were moistened continuously with tap water [47-49].

The scope of the polarization experiment is to understand better the specific characteristics of the systems under examination in order to measure their power outputs. Figure 7.B shows the power curves generated, this graph gives us the possibility to assess the maximum power transfer point (MPP), which is the maximum peak of each power curve and corresponds to the optimum resistance value that can give this output. Based on the results, it is evident that airdry clay had the highest power output at $130 \mu \mathrm{W}$ followed by air-dry Fimo ${ }^{\mathrm{TM}}$ with $111 \mu \mathrm{W}$. These results were in accordance with the real time data of the initial thirty days shown above (Section 3.3.2) proving that the air-dry membranes generated the highest amount of power output. The two underperforming MFCs were the control ones with terracotta (73 $\mu \mathrm{W})$ and CEM giving $50 \%$ less than the air-dry clay $(66 \mu \mathrm{W})$.

Comparing the power density of the MFCs reported herein with other MEA-based MFCs in the literature, the 3D-printable ones are showing promising results. In particular a study on tubular MFCs with air breathing cathodes based on CEM-MEA had a power density of $5 \mathrm{~W} \mathrm{~m}^{-3}$ (based on the anodic liquid volume of $200 \mathrm{~mL}$ ) [50]. This output is $0.2 \mathrm{~W} \mathrm{~m}^{-3}$ less than the air-dry clayMEA of this study, calculated based on a reactor volume of $25 \mathrm{~mL}$. Additionally apart from the advantage over the power density, the MEA used in the aforementioned study [49] was fabricated using carbon cloth coated with a mixture of Pt powder and carbon black bonded together with Nafion resin, which inherently increases the cost.

Following polarization analysis, the optimal external resistance was identified $(1 \mathrm{k} \Omega)$. Once the MFCs were connected to this lower resistance value, the performance levels begun to diverge and Fimo ${ }^{\mathrm{TM}}$ was producing the highest power output as can be seen in Figure 6 . Although after the change in external resistance, the results of the polarization differed from the realtime data (day 30 onwards) and Fimo $^{\mathrm{TM}}$ ended up outperforming the air-dry, in all cases the soft materials were operating better than the conventional cation exchange membrane.

\subsection{COD Analysis}

Following the increase in performance due to the external loading shift, a chemical oxygen demand (COD) analysis was conducted to observe the rate of COD decrease within a 24 hour period. On the eleventh day following the switch in external resistance (forty-second day of the entire experiment), prior to replenishing the anode chamber with the $25 \mathrm{~mL}$ of urine a sample was taken for COD analysis. In parallel to that, a sample from that urine $(25 \mathrm{~mL})$ was kept in a closed glass bottle on the bench to observe the decrease in COD without being treated in MFC. The following day, a sample of the effluent of all the MFCs was taken and analysed. The results of this analysis are presented in Figure 8.A. which shows that MFCs with air-dry Fimo ${ }^{\mathrm{TM}}$ MEA had a decrease of almost $82 \pm 1 \%$ in COD which was $4 \%$ higher than air-dry clay and terracotta. CEM based MFCs resulted in $63 \pm 1 \%$ COD decrease. The control COD reduction occurring in the closed glass bottle after 24 hours was $4.7 \%$; this value was 
deducted from the overall percentage decreases of all MFCs. This was in order to demonstrate the decrease in COD, which was induced due to the bioelectrocatalytic activity of the electroactive microorganisms presented in the anode and also by fermentative floating microorganisms.
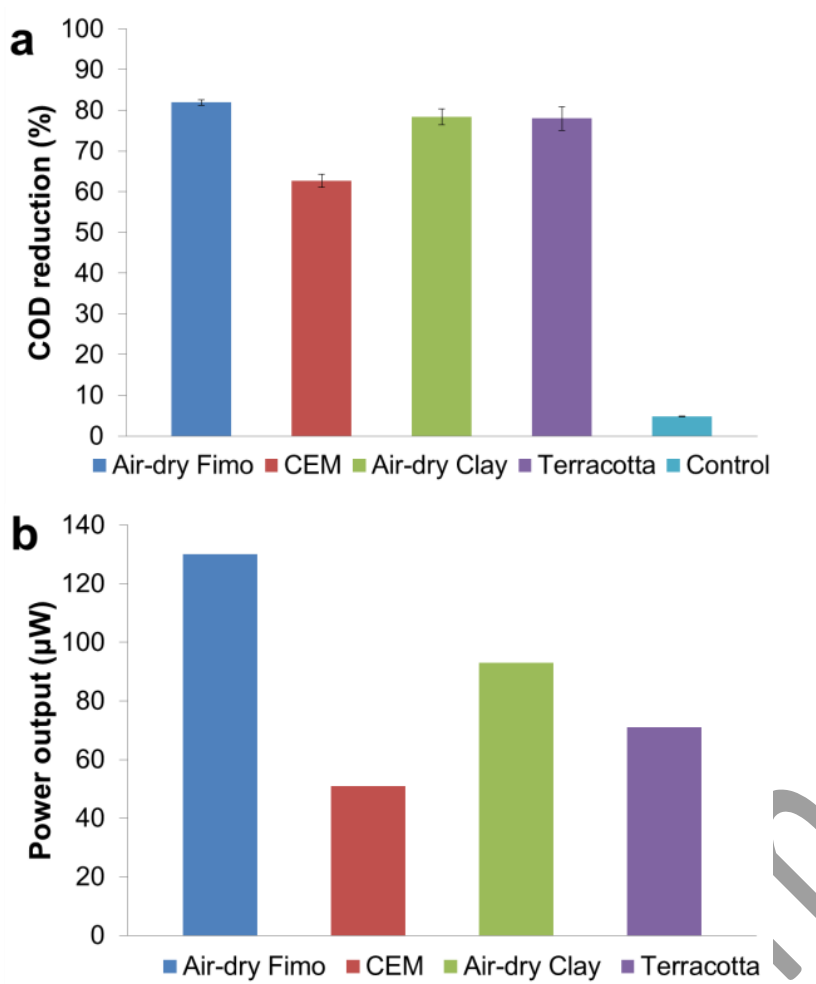

Figure 8. COD reduction results and power output at the time of sampling. a) Percentage of COD reduction of fresh urine within 24 hours in an MFC and in a closed glass bottle (control). b). Power Output of the MFCs at the moment that the samples for COD analysis were taken.

442

443

444

445

446

447

448

449

450

451

452

453

454

455

456

The results of the COD analysis are in agreement with the real time data of that period (day 42), which confirm and support the literature which reports that the highest the power output the highest the COD removal [51]. For clarity Figure 8.B shows the power output of the MFCs at the time that the samples were taken. Based on that in terms of power output Fimo ${ }^{\mathrm{TM}}$ was at $130 \mu \mathrm{W}$, air-dry clay and terracotta performed $29 \%$ and $45 \%$ lower than Fimo $^{\mathrm{TM}}$ whereas CEM had a $60 \%$ less power output than the aforementioned $(51 \mu \mathrm{W})$. Figure 8 demonstrates clearly the correlation of power output to COD reduction and adds an extra value to the feasibly of those MEAs as alternative conductive separators of MFCs.

The capability of MFCs in treating wastewater and pollutants [52-54] while generating electricity is one of the attractive characteristics of the technology that make it a favourable off-grid source of electricity and sanitation.

\subsection{Cost Analysis}

As microbial fuel cell is a technology producing low quantity of electricity, particular attention needs to be given to the overall cost needed in maximizing the performance while minimizing 
the costs. In this section, the cost of the membranes is illustrated and discussed (Figure 9). The cost of the ceramic membranes was calculated considering 1 kilo of raw materials. More specifically, at the moment of purchase air-dry Fimo ${ }^{\mathrm{TM}}$ cost $4.94 £ \mathrm{~kg}^{-1}$, air-dry clay cost 3.75 $£ \mathrm{~kg}^{-1}$ while terracotta was the least expensive of all as it was $33 \%$ cheaper than air-dry clay and roughly $50 \%$ cheaper than air-dry Fimo ${ }^{\mathrm{TM}}$. The cost of the latter was in fact $2.52 £ \mathrm{~kg}^{-1}$. The CEM cost was considered to be $188 £ \mathrm{~m}^{-2}\left(250 \$ \mathrm{~m}^{-2}\right)$ according to the supplier. Each membrane was weighed during fabrication and therefore the composition was known. In the case of CEM, a total area of $25 \mathrm{~cm}^{-2}$ was used. In order to fabricate the ceramic membranes, $6 \mathrm{~g}, 8 \mathrm{~g}$ and $10 \mathrm{~g}$ of air-dry Fimo $^{\mathrm{TM}}$, air-dry clay and terracotta respectively were used. Consequently, the overall cost for each membrane (with an area of $25 \mathrm{~cm}^{-2}$ ) was similar for air-dry Fimo ${ }^{\mathrm{TM}}$ and air-dry clay at $£ 0.030$ per membrane and terracotta being slightly lower at $£ 0.025$ per membrane mainly due to the lower cost of the raw material. CEM was the most expensive costing $£ 0.78$ per membrane (Figure 9.A). This means that it is possible to fabricate 26 air-dry Fimo ${ }^{\mathrm{TM}}$ /air-dry clay membranes or 31 terracotta membranes for every single CEM membrane for the same cost.
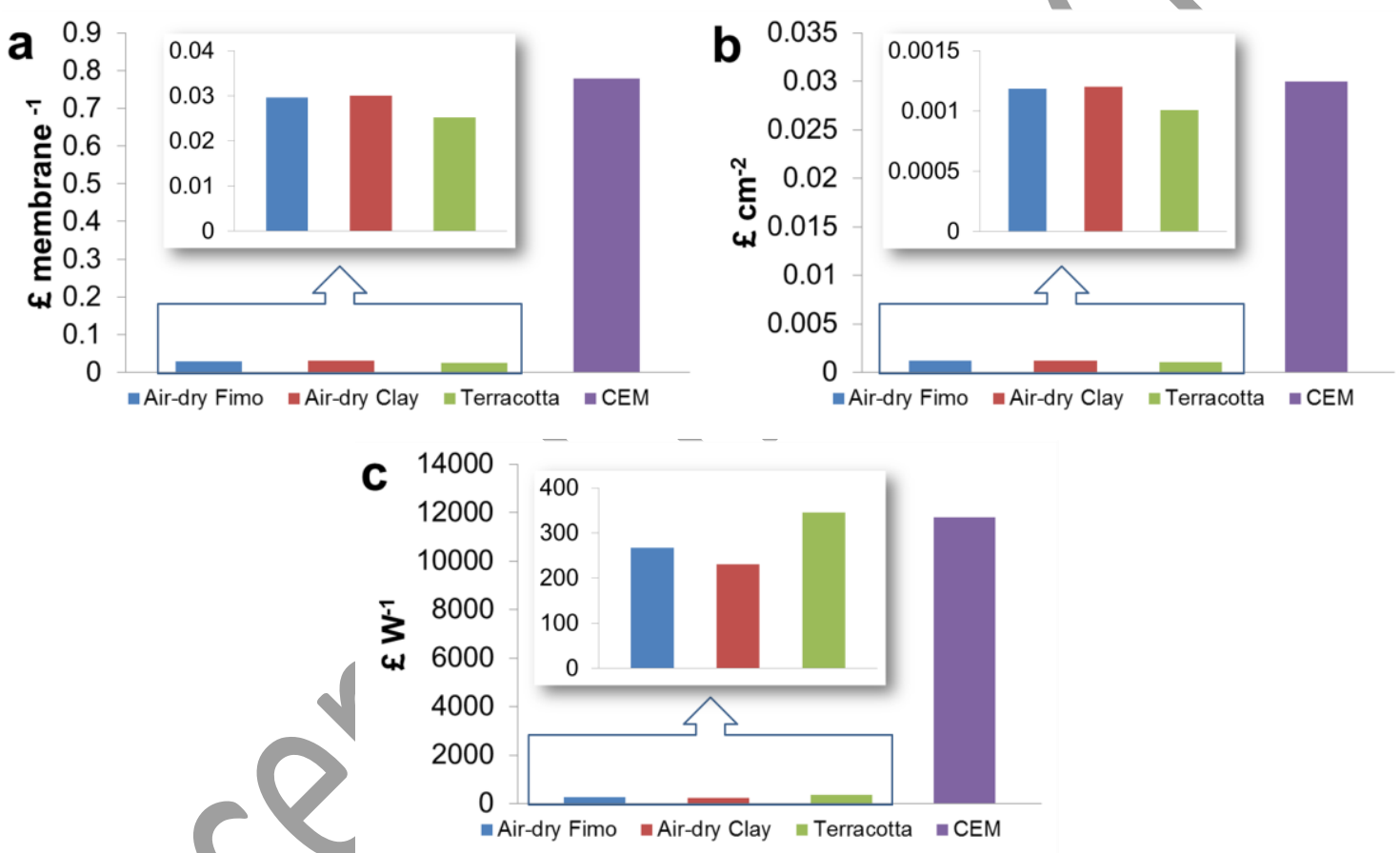

Figure 9. Cost analysis of the membranes. a) Overall cost of the membranes, b) cost of the membrane for unit of area c) and cost of the membrane for unit of power produced.

Another important aspect to consider is the cost of the membrane density meaning the cost of the membrane per $\mathrm{cm}^{2}$. The results are shown in Figure 9.B. The trend reflects the cost of the raw materials with terracotta having the lowest cost per surface area and CEM the highest. Particularly, the cost for terracotta was roughly 0.1 pence per $\mathrm{cm}^{2}\left(10 £ \mathrm{~cm}^{-2}\right)$ followed by airdry Fimo ${ }^{\mathrm{TM}}$ and air-dry clay with a cost of roughly 0.12 pence per $\mathrm{cm}^{2}\left(12 £ \mathrm{~m}^{-2}\right)$ and CEM thirty times higher than that $\left(\approx 300 £ \mathrm{~m}^{-2}\right)$.

Finally, the cost of membrane for each Watt produced was also calculated (Figure 9.C). The power from the peak of power curves (Figure 7.B) was considered in $130 \mu \mathrm{W}, 111 \mu \mathrm{W}, 73 \mu \mathrm{W}$ and $60 \mu \mathrm{W}$ for air-dry clay, air-dry Fimo ${ }^{\mathrm{TM}}$, terracotta and CEM respectively. Due to the higher performance, air-dry clay had the higher value of cost per power produced among the 
achieved by air-dry Fimo ${ }^{\mathrm{TM}}$ with $267 £ \mathrm{~W}^{-1}$. Terracotta had a cost per W produced of $345 £ \mathrm{~W}^{-}$ ${ }^{1}$ and CEM had an astonishing value of $11818 £ \mathrm{~W}^{-1}$. The cost per W produced of CEM was 34, 44, 51 times higher compared to terracotta, air-dry Fimo ${ }^{\mathrm{TM}}$ and air-dry clay respectively. Among the three clay-based membranes, the most cost-effective material tested was air-dry clay. The cost per $\mathrm{W}$ produced was $14 \%$ and $33 \%$ better compared to air-dry Fimo ${ }^{\mathrm{TM}}$ and terracotta respectively. Air-dry Fimo ${ }^{\mathrm{TM}}$, air-dry clay and terracotta seems to be very promising cost-effective membranes materials that can replace the more expensive and not environmentally-friendly polymeric membranes. It must be noted that the cost of kilning or shipping from abroad were not taken into account for these economic calculations.

\subsection{D-printing MEAs using EvoBot.}

EvoBot (Figure 10.A) is a RepRap open-source 3D-printer modified successfully to operate like a robot for culturing and maintaining Microbial Fuel Cells (MFCs) based on an established feedback loop between the MFC systems and the python controlled platform [55]. EvoBot can host a large number of MFCs (24) on its experimental arena where it can gather data about the MFCs and react through a feedback loop to set thresholds (voltage output). This improves the performance of the MFCs by providing nutrient supply only when needed. So far this type of liquid handling robot-MFC interaction, based on the feedback loop mechanism, has enabled the study the adaptability and stability of those systems [55].

Since EvoBot is a 3D-printer turned to robot it still holds its 3D-printing capabilities thus it can extrude (3D-print) parts for MFCs with the ultimate aim to monolithically print and nurture those already made MFCs. Having this in mind, the two air-dry materials tested as alternative membranes -against conventional polymeric cation exchange membranes and fired terracotta- come in the form of soft modelling clay, which makes them suitable for extrusion from the EvoBot platform (Figure 10.B). As the uncured form of the electrode material is also fluid, it can be applied using EvoBot by incorporating a brush/roller on the actuation layer of 


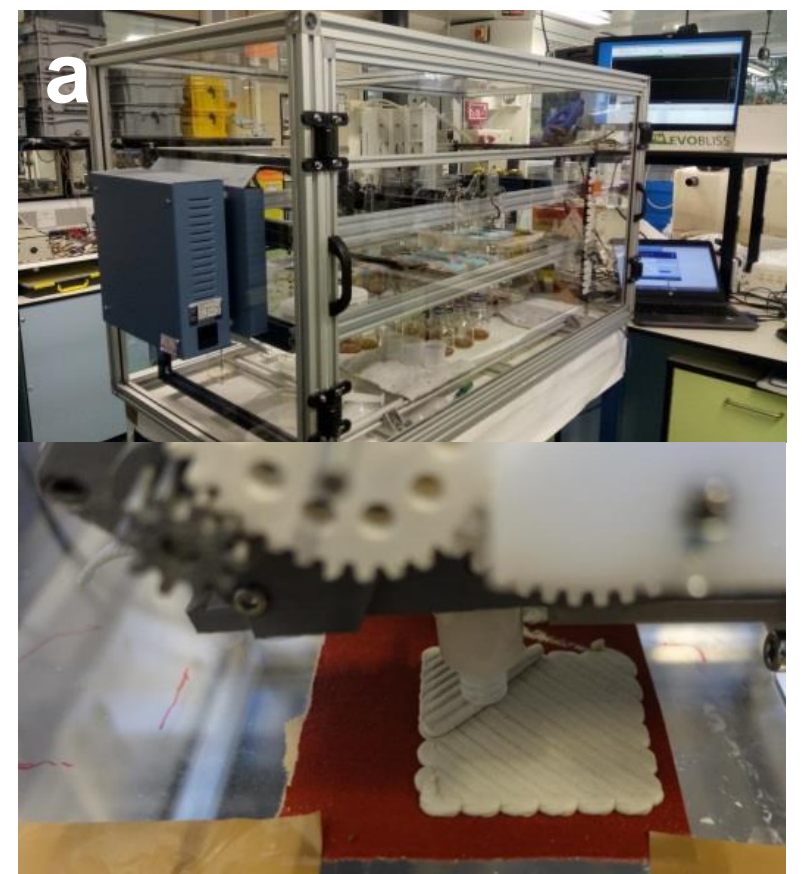

Figure 10. EvoBot Rep-Rap 3D-printer. a) EvoBot within is Evo-world enclosure performing experiments on MFCs under controlled conditions b) EvoBot with an adapted extruder 3D-prints Fimo ${ }^{\mathrm{TM}}$ membranes. Source: www.evobliss-project.eu.

\subsection{Conclusions}

511 This study explored the idea of using air-dry based materials such as Fimo ${ }^{\mathrm{TM}}$ and clay to 512 fabricate membrane electrode assemblies for Microbial Fuel Cells (MFC) which were then compared against two of the most popularly used materials in the field, cation exchange membrane (CEM) and kilned red terracotta. Through this study it has been successfully shown that MFCs with air-dry clay based MEAs can produce up to $50 \%$ more power than the controls. Since the MFC technology relies on low-cost materials, due to the small amount of electricity generated per MFC unit, the fact that terracotta, air-dry Fimo ${ }^{\mathrm{TM}}$ and air-dry clay were $40 \pm 10$ times cheaper than CEM (per Watt produced), adds an extra advantage in using these materials. In addition those MFCs had a COD reduction of nearly $80 \%$ which was $20 \%$ more than what the CEM based MFCs achieved. At last, the capabilities of those air-cured materials open another promising avenue to the MFC research as their fabrication can be done with 3D printing and/or extrusion techniques using the EvoBot platform. Thus it is envisaged that monolithically 3D-printed MFCs are feasible and can potentially emerge from platforms such as EvoBot.

\section{Acknowledgments}

The authors would like to thank the European Commission for the financial support of this work through the FP7-ICT, grant agreement 611640 (EVOBLISS). Also special thanks are given to Dr Amir Bolouri and Tamsila Tauqir for the hardness analysis of the samples as well as Dr Andres Faina and Mathias Schmidt for developing the Fimo ${ }^{\mathrm{TM}}$ extruder. The authors would also like to thank Associate Prof. Carlo Santoro for his input in the writing process of the paper and Dr Jonathan Winfield for providing his constructive feedback.

\section{References}


[1] International Energy Agency. World Energy Outlook 2017. OECD; 2017. doi:10.1787/weo-2017-en.

[2] Potter M. Electrical Effects Accompanying the Decomposition of Organic Compounds Published by: The Royal Society Electrical Effects accompanying the Decormposition of Organic. Proc R Soc London Ser B, Contain Pap a Biol Character, 1911;84:26076.

[3] Allen RM, Bennetto HP. Microbial fuel-cells: Electricity Production from Carbohydrates. Appl Biochem Biotechnol 1993;39:27-40.

[4] Bennetto HP. Electricity generation by microorganisms. Biotechnol Educ 1990;1:1638.

[5] Jung S, Regan JM. Comparison of anode bacterial communities and performance in microbial fuel cells with different electron donors. Appl Microbiol Biotechnol 2007;77:393-402. doi:10.1007/s00253-007-1162-y.

[6] Hassan SHA, Gad El-Rab SMF, Rahimnejad M, Ghasemi M, Joo JH, Sik-Ok Y, et al. Electricity generation from rice straw using a microbial fuel cell. Int $J$ Hydrogen Energy 2014;39:9490-6. doi:10.1016/j.ijhydene.2014.03.259.

[7] Bennetto H, Mason JR, Stirling JL, Thurston CF. Miniature microbial biobatteries. Power Sources 1987;11:373-380.

[8] Du Z, Li H, Gu T. A state of the art review on microbial fuel cells: A promising technology for wastewater treatment and bioenergy. Biotechnol Adv 2007;25:464-82. doi:10.1016/j.biotechadv.2007.05.004.

[9] Ieropoulos IA, Stinchcombe A, Gajda I, Forbes S, Merino-Jimenez I, Pasternak G, et al. Pee power urinal - microbial fuel cell technology field trials in the context of sanitation. Environ Sci Water Res Technol 2016;2:336-43. doi:10.1039/C5EW00270B.

[10] Papaharalabos G, Greenman J, Melhuish C, leropoulos I. A novel small scale Microbial Fuel Cell design for increased electricity generation and waste water treatment. Int J Hydrogen Energy 2015;40:4263-8. doi:10.1016/j.ijhydene.2015.01.117.

[11] leropoulos I, Greenman J, Melhuish C. Microbial fuel cells based on carbon veil electrodes: Stack configuration and scalability. Int J Energy Res 2008;32:1228-40. doi:10.1002/er 1419 .

[12] Wei J, Liang P, Huang X. Recent progress in electrodes for microbial fuel cells. Bioresour Technol 2011;102:9335-44. doi:10.1016/j.biortech.2011.07.019.

[13] You J, Santoro C, Greenman J, Melhuish C, Cristiani P, Li B, et al. Micro-porous layer (MPL)-based anode for microbial fuel cells. Int J Hydrogen Energy 2014;39:21811-8. doi:10.1016/j.ijhydene.2014.07.136.

[14] Guerrini E, Grattieri M, Trasatti SP, Bestetti M, Cristiani P. Performance explorations of single chamber microbial fuel cells by using various microelectrodes applied to biocathodes. Int J Hydrogen Energy 2014;39:21837-46. doi:10.1016/J.IJHYDENE.2014.06.132.

[15] Santoro C, Agrios A, Pasaogullari U, Li B. Effects of gas diffusion layer (GDL) and micro porous layer (MPL) on cathode performance in microbial fuel cells (MFCs). Int $\mathrm{J}$ Hydrogen Energy 2011;36:13096-104. doi:10.1016/j.ijhydene.2011.07.030. 
[16] Chaudhuri SK, Lovley DR. Electricity generation by direct oxidation of glucose in mediatorless microbial fuel cells. Nat Biotechnol 2003;21:1229-32. doi:10.1038/nbt867.

[17] Aelterman P, Versichele M, Marzorati M, Boon N, Verstraete W. Loading rate and external resistance control the electricity generation of microbial fuel cells with different three-dimensional anodes. Bioresour Technol 2008;99:8895-902. doi:10.1016/j.biortech.2008.04.061.

[18] Santoro C, Guilizzoni M, Correa Baena JP, Pasaogullari U, Casalegno A, Li B, et al. The effects of carbon electrode surface properties on bacteria attachment and start up time of microbial fuel cells. Carbon N Y 2014;67:128-39. doi:10.1016/j.carbon.2013.09.071.

[19] Santoro C, Artyushkova K, Gajda I, Babanova S, Serov A, Atanassov P, et al. Cathode materials for ceramic based microbial fuel cells (MFCs). Int J Hydrogen Energy 2015;40:14706-15. doi:10.1016/j.ijhydene.2015.07.054.

[20] Merino-Jimenez I, Santoro C, Rojas-Carbonell S, Greenman J, leropoulos I, Atanassov P. Carbon-Based Air-Breathing Cathodes for Microbial Fuel Cells. Catalysts 2016;6:127. doi:10.3390/catal6090127.

[21] Wang Z, Mahadevan GD, Wu Y, Zhao F. Progress of air-breathing cathode in microbial fuel cells. J Power Sources 2017;356:245-55. doi:10.1016/j.jpowsour.2017.02.004.

[22] Santoro C, Arbizzani C, Erable B, leropoulos I. Microbial fuel cells: From fundamentals to applications. A review. J Power Sources 2017;356:225-44. doi:10.1016/j.jpowsour.2017.03.109.

[23] Sealy C. The problem with platinum. Mater Today 2008;11:65-8. doi:10.1016/S13697021(08)70254-2.

[24] Ieropoulos I, Winfield J, Gajda I, Walter A, Papaharalabos G, Jimenez IM, et al. The Practical Implementation of Microbial Fuel Cell Technology. Elsevier Ltd.; 2015. doi:10.1016/B978-1-78242-375-1.00012-5.

[25] Yang W, Li J, Zhang L, Zhu X, Liao Q. A monolithic air cathode derived from bamboo for microbial fuel cells. RSC Adv 2017;7:28469-75. doi:10.1039/c7ra04571a.

[26] Yang W, Li J, Ye D, Zhu X, Liao Q. Bamboo charcoal as a cost-effective catalyst for an air-cathode of microbial fuel cells. Electrochim Acta 2017;224:585-92. doi:10.1016/j.electacta.2016.12.046.

[27] Zhang Y, Yang W, Fu Q, Li J, Zhu X, Liao Q. Performance optimization of microbial fuel cells using carbonaceous monolithic air-cathodes. Int J Hydrogen Energy 2018:17. doi:10.1016/j.jhydene.2018.07.132.

[28] Walter XA, Gajda I, Forbes S, Winfield J, Greenman J, leropoulos I. Scaling-up of a novel, simplified MFC stack based on a self-stratifying urine column. Biotechnol Biofuels 2016;9:93. doi:10.1186/s13068-016-0504-3.

[29] Harnisch F, Schröder U. Selectivity versus mobility: Separation of anode and cathode in microbial bioelectrochemical systems. ChemSusChem 2009;2:921-6. doi:10.1002/cssc.200900111.

[30] Ghasemi M, Wan Daud WR, Ismail M, Rahimnejad M, Ismail AF, Leong JX, et al. Effect of pre-treatment and biofouling of proton exchange membrane on microbial fuel 
cell performance. Int J Hydrogen Energy 2013;38:5480-4.

doi:10.1016/j.ijhydene.2012.09.148.

[31] Flimban SGA, Hassan SHA, Rahman MM, Oh SE. The effect of Nafion membrane fouling on the power generation of a microbial fuel cell. Int J Hydrogen Energy 2018:1-9. doi:10.1016/j.jhydene.2018.02.097.

[32] Xu J, Sheng GP, Luo HW, Li WW, Wang LF, Yu HQ. Fouling of proton exchange membrane (PEM) deteriorates the performance of microbial fuel cell. Water Res 2012;46:1817-24. doi:10.1016/j.watres.2011.12.060.

[33] Winfield J, Gajda I, Greenman J, leropoulos I. A review into the use of ceramics in microbial fuel cells. Bioresour Technol 2016;215:296-303. doi:10.1016/j.biortech.2016.03.135.

[34] Yousefi V, Mohebbi-Kalhori D, Samimi A. Ceramic-based microbial fuel cells (MFCs): A review. Int J Hydrogen Energy 2017;42:1672-90. doi:10.1016/j.ijhydene.2016.06.054.

[35] Nandy A, Kumar V, Mondal S, Dutta K, Salah M, Kundu PP. Performance evaluation of microbial fuel cells: Effect of varying electrode configuration and presence of a membrane electrode assembly. N Biotechnol 2015;32:272-81. doi:10.1016/j.nbt.2014.11.003.

[36] Faíña A, Nejatimoharrami F, Stoy K, Theodosiou P, Taylor B, leropoulos I. EvoBot: An Open-Source, Modular Liquid Handling Robot for Nurturing Microbial Fuel Cells. Proc. Artif. Life Conf. 2016, 2016, p. 626-33.

[37] Ieropoulos I, Theodosiou P, Taylor B, Greenman J, Melhuish C. Gelatin as a promising printable feedstock for microbial fuel cells (MFC). Int J Hydrogen Energy 2017;42:1783-90. doi:10.1016/j.ijhydene.2016.11.083.

[38] Winfield J, Chambers LD, Stinchcombe A, Rossiter J, leropoulos I. The power of glove: Soft microbial fuel cell for low-power electronics. J Power Sources 2014;249:327-32. doi:10.1016/j.jpowsour.2013.10.096.

[39] Clinton DJ, Morrell R. Hardness testing of ceramic materials. Mater Chem Phys 1987;17:461-73. doi:10.1016/0254-0584(87)90096-4.

[40] Degrenne N, Buret F, Allard B, Bevilacqua P. Electrical energy generation from a large number of microbial fuel cells operating at maximum power point electrical load. J Power Sources 2012;205:188-93. doi:10.1016/j.jpowsour.2012.01.082.

[41] Winfield J, leropoulos I, Greenman J, Dennis J. The overshoot phenomenon as a function of internal resistance in microbial fuel cells. Bioelectrochemistry $2011 ; 81: 22-$ 7. doi:10.1016/j.bioelechem.2011.01.001.

[42] Pasternak G, Greenman J, leropoulos I. Comprehensive Study on Ceramic Membranes for Low-Cost Microbial Fuel Cells. ChemSusChem 2016;9:88-96. doi:10.1002/cssc.201501320.

[43] Rossiter J, Winfield J, leropoulos I. Here today, gone tomorrow: biodegradable soft robots 2016;9798:97981S. doi:10.1117/12.2220611.

[44] Kaiyu Industrial LTD. Micronized Graphite 2018.

http://www.kyugraphite.com/micronized-graphite-3276941.html.

[45] Winfield J, Chambers LD, Rossiter J, Greenman J, leropoulos I. Urine-activated 
origami microbial fuel cells to signal proof of life. J Mater Chem A 2015;3:7058-65. doi:10.1039/C5TA00687B.

[46] Papaharalabos G, Greenman J, Melhuish C, Santoro C, Cristiani P, Li B, et al. Increased power output from micro porous layer (MPL) cathode microbial fuel cells (MFC). Int J Hydrogen Energy 2013;38:11552-8. doi:10.1016/j.ijhydene.2013.05.138.

[47] Logan B. Microbial Fuel Cells. Hoboken, New Jersey: John Wiley \& Sons; 2008.

[48] leropoulos I, Greenman J, Melhuish C. Improved energy output levels from smallscale Microbial Fuel Cells. Bioelectrochemistry 2010;78:44-50. doi:10.1016/j.bioelechem.2009.05.009.

[49] leropoulos I, Melhuish C, Greenman J. Artificial gills for robots: MFC behaviour in water. Bioinspir Biomim 2007;2:S83-93. doi:10.1088/1748-3182/2/3/S02.

[50] Kim JR, Premier GC, Hawkes FR, Dinsdale RM, Guwy AJ. Development of a tubular microbial fuel cell (MFC) employing a membrane electrode assembly cathode. $\mathrm{J}$ Power Sources 2009;187:393-9. doi:10.1016/j.jpowsour.2008.11.020.

[51] Zhang X, He W, Ren L, Stager J, Evans PJ, Logan BE, COD removal characteristics in air-cathode microbial fuel cells. Bioresour Technol 2015;176:23-31. doi:10.1016/j.biortech.2014.11.001.

[52] Ahn Y, Logan BE. Effectiveness of domestic wastewater treatment using microbial fuel cells at ambient and mesophilic temperatures. Bioresour Technol 2010;101:469_ 75. doi:10.1016/j.biortech.2009.07.039.

[53] Gajda I, Greenman J, Melhuish C, leropoulos IA. Electricity and disinfectant production from wastewater: Microbial Fuel Cell as a self-powered electrolyser. Sci Rep 2016;6:25571. doi:10.1038/srep25571.

[54] Liu Y, Liu H, Wang C, Hou SX, Yang N. Sustainable energy recovery in wastewater treatment by microbial fuel cells: Stable power generation with nitrogen-doped graphene cathode. Environ Sci Technol 2013;47:13889-95. doi:10.1021/es4032216.

[55] Theodosiou P, Faina A, Nejatimoharrami F, Stoy K, Greenman J, Melhuish C, et al. EvoBot: Towards a Robot-Chemostat for Culturing and Maintaining Microbial Fuel Cells (MFCs). Biomim. Biohybrid Syst., Springer, Cham; 2017, p. 453-64. doi:10.1007/978-3-319-63537-8_38. 